\title{
Information and Perception towards Emergency Contraception among Female Adolescent Students in Secondary School of Kathmandu District
}

\author{
Binod Kumar Karki ${ }^{1}$
}

\begin{abstract}
Emergency Contraception is a method used to avoid pregnancy after unprotected sexual intercourse or a contraceptive accident to prevent an unwanted pregnancy. This method has potential to prevent up to $75 \%$ of unplanned pregnancies. The aim of this study is to assess the information and perception towards emergency contraception among female adolescent students in secondary school. Secondary classes (+2 Wing) run by Koteshwor Multiple Campus was selected as study area purposively. The study was conducted on November 2018 to December 2018. The study was based on descriptive cross-sectional research design. Self-administered structure and pre-tested questionnaire were used to obtain information and perception from 220 study participants were selected by simple random sampling technique. After data collection, the data was coded, entered, and analyzed by using SPSS version 20. The study shows that 84.5 percentages of the female adolescent students had heard about emergency contraceptive. 85 percentages of them identified the correct timing of use within 72 hours of unsafe sexual contact. 69 percentages respondents said they are ready to use emergency contraceptive if required. There is significant relation between educational level and information of emergency contraceptive. The level of information of emergency contraception among female adolescent students was high but perception towards that was negative while comparing to other studies. Thus, health education intervention regarding information and positive perception towards emergency contraception is needed to female adolescent students of secondary school.
\end{abstract}

Keywords: Information, perception, emergency contraception, adolescent, pregnancy

\section{Introduction}

Adolescent is a transitional period of life ranging from 10 to 19 years (WHO, 2001). Globally, adolescents age (10-19) account for nearly one fifth (18\%) of the total population (UN, 2011). Every fifth of people in the world is adolescent who have their specific issues and problems like any other group of age (Family Health Division,

1 Mr. Karki is a lecturer of Health Education at Koteshwor Multiple Campus, Koteshwor Kathmandu affiliated to T. U. He is a Ph D. scholar at Graduate School of Education, T. U. 
2000). In Nepal, adolescents comprise 24 percent which is a larger proportion to the global comparison (Ministry of Health and Population, 2011). The government of Nepal has recognized adolescents as a vulnerable population with specific sexual and reproductive health needs, however, only a limited number of the program has been implemented targeting these age groups (Khatiwada et al. 2013).

One of the studies in Nepal revealed that 10 to 20 percent of adolescents reported participating in pre-marital sex, yet only 9 percent of them reported using a method of contraception (Centre for Research on Environment Health and Population Activities, 2004). Nepal has a high level of unintended pregnancies (33\%) among currently married women of reproductive age. Unintended pregnancies among young married women (15-24 years of age) are also significantly high in the country. Unintended pregnancy in an unmarried adolescent girl can either result in induced or early and unplanned marriage (CREHPA, 2006). Whatever understanding the adolescents have is incomplete, inconsistent, and confused. Unsafe/unprotected and early sexual relations are highly responsible for the problems of unwanted pregnancy, childbirth, and other adverse consequences (Pathak, 2014).Emergency contraception (EC) is the only method women can use to prevent pregnancy after they have had unprotected sexual intercourse, have experienced a contraceptive failure, have remembered too late that they have forgotten to take their birth control pills, or have been forced to have sex against their will to prevent unwanted pregnancy in the first few days (Elizabeth \& James, 2012).

It is a method used to avoid pregnancy after unprotected sexual intercourse or a contraceptive accident to prevent unwanted pregnancy (Thapa, 2013). Emergency contraception is found to be effective if used within 72 hours after unprotected sexual intercourse (Kongnyuy, 2007). It offers women a last chance to prevent pregnancy andshould not be used as a regular family planning method but should be used only in emergency time. It has the advantage of preventing unintended pregnancy and prevents induced abortion after unprotected sexual intercourse but the majority of the female was not knowledgeable about emergency contraceptive pills (Abraha et al. 2019). Addressing adolescent pregnancy is Important for achieving the national health care plan of developing countries like Nepal. Millions of unwanted pregnancy and unsafe abortion could be averted if emergency contraception were easily available. Thus, unwanted pregnancy and abortion are the major public health problems in our country and also throughout the world. Although emergency contraception is not recommended as a routine family planning method, it is a very useful method after unprotected sexual intercourse to reduce the chance of unplanned or unwanted pregnancies. Emergency contraception is most useful where there is a failure or barrier of methods such as slippage and breakage of condoms, 
or when sexual intercourse was unpremeditated. Thus, emergency contraception is an effective means of preventing unwanted pregnancies but unfortunately, the majority of the school/college going student are unaware of it (Adhikari, R. 2009).

Nepal has a high incidence of unplanned pregnancies and unsafe abortion particularly among adolescents and currently married women of reproductive age (15-24 years of age.) (Thapa et al.2015). Emergency contraception offers a final opportunity to prevent unwanted pregnancy, reduce mortality, and morbidity due to the consequences of unsafe abortion in adolescents. Adolescent pregnancy is associated with adverse maternal, fetal, and neonatal outcomes (Somba et al. 2014).

To prevent these problems after unprotected sexual intercourse emergency contraception plays an important role. But due to lack of adequate information many females are exposed to different health and health-related risks. Also, there are a few data available on female's knowledge and attitude towards emergency contraceptive or it is not well studied as compared to its significance. The findings of this study could help plan to reduce unwanted pregnancy, unsafe abortion, and its complication, improve the sexual and reproductive health of female adolescent students of secondary schools. Thus in this study, the author aimed to assess the information and perception towards emergency contraception among female adolescent students of secondary school.

\section{Methods and Materials}

This research was institutionally based; descriptive cross-sectional study design was used to access the information and perception towards emergency contraception among the female adolescent students of grade eleven and twelve from Koteshwor Multiple Campus, of Kathmandu Metropolitan City. The anonymity of subjects was maintained by asking them not to write their name and students were not forced to participate in the study. Before providing a questionnaire, students were consented and briefed about the purpose of the study and the method of filling the questionnaire. There was not any manipulation during the filling up of the questionnaire. The filled questionnaires were collected after completion. Research approval and ethical clearance were obtained from the concerned authority. The study was conducted in November 2018-December 2018. A purposive sampling technique was used to select the study area. A stratified random sampling technique was employed from each class found in college and then the sample unit was taken from a total of 519 female adolescent students using a simple random sampling system. Then the required sample size was selected by the lottery method. The total population of the study is less than 10,000, the minimum sample size (n') were obtained by the following formula: 
$n^{\prime}=\mathrm{n} /(1+\mathrm{n} / \mathrm{N})$ Where

$\mathrm{n} \prime=$ minimum sample size $=383 /(1+383 / 519)$

$\mathrm{n}=$ determined sample size $=220$

$\mathrm{N}=$ total female students in the school/college n' $=220$

Therefore, 220 female adolescent students have participated in the study. So, the sample size for the study was 220 female adolescent students. A self-structured questionnaire was used to obtain data from the respondents. The questionnaire contained 17 question items and it was divided into three sections: 1) socio-demographic data; 2) information on emergency contraception and 3) perception of emergency contraception. The collected data were analyzed using the SPSS program version 20. Descriptive Statistics like frequency, percentage, as well as inferential statistics like the Chi-square test used to analyze the data. Cross-tabulation of variables was also done. A P-value of less than 0.05 was considered as statistically significant.

\section{Results}

Table 1: Socio-demographic Characteristics of Respondents ( $n=220)$

\begin{tabular}{|c|c|c|}
\hline Variables & Frequency & Percentage \\
\hline \multicolumn{3}{|l|}{ Age Group } \\
\hline Age $14-15$ & 5 & 2.3 \\
\hline Age $16-17$ & 107 & 48.6 \\
\hline Age 18-19 & 108 & 49.1 \\
\hline \multicolumn{3}{|c|}{\begin{tabular}{|l} 
Educational Status \\
\end{tabular}} \\
\hline Grade-11 & 107 & 48.6 \\
\hline Grade- 12 & 113 & 51.4 \\
\hline \multicolumn{3}{|l|}{ Religion } \\
\hline Hindu & 169 & 76.8 \\
\hline Buddhist & 29 & 13.2 \\
\hline Christian & 14 & 6.4 \\
\hline Kirat & 8 & 3.6 \\
\hline \multicolumn{3}{|l|}{ Occupation } \\
\hline Student & 204 & 92.7 \\
\hline Service & 16 & 7.3 \\
\hline \multicolumn{3}{|c|}{ Caste/Ethnicity } \\
\hline Chettri & 78 & 35.5 \\
\hline Brahmin & 41 & 18.6 \\
\hline
\end{tabular}




\begin{tabular}{|c|c|c|}
\hline Newar & 19 & 8.6 \\
\hline Tamang & 27 & 12.3 \\
\hline Gurung & 6 & 2.7 \\
\hline Rai/Limbu & 17 & 7.7 \\
\hline Magar & 12 & 5.5 \\
\hline Sherpa & 4 & 1.8 \\
\hline Dalit & 12 & 5.5 \\
\hline Tharu & 4 & 1.8 \\
\hline Total & 220 & 100 \\
\hline
\end{tabular}

Table 1 presents the Socio-demographic characteristics of respondents. It is seen that all the respondents are female adolescents the age of 14-19 with a mean age of 17.5 years, where the majority 108 (49.1\%) was in the age group 18-19 years. The distribution of respondents by educational status indicated that about $113(51.4 \%)$ of them were Grade twelve and the rest 107(48.6\%) were from Grade eleven. About respondents' religion, $169(76.8 \%)$ of the respondents were Hindu followed by Buddhist 29 (13.2\%), Christian14 (6.4\%), and Kirat 8 (3.6\%) in which 78 (35.5\%) respondents were Chhetri while 41 (18.6\%) were Brahmin. Majority 204 (92.7\%) of respondents' occupations were only students.

Table-2 Respondents Information on Emergency Contraception $(\mathrm{n}=220)$

\begin{tabular}{|l|c|c|}
\hline \multicolumn{2}{|c|}{ Variables } & Frequency \\
\hline Have you heard about emergency Contraception? \\
\hline Yes & 186 & 84.5 \\
No & 34 & 15.5 \\
\hline What are your sources of information about Emergency Contraception? \\
\hline Friends & 54 & 24.5 \\
Television/Radio & 36 & 16.4 \\
Health worker & 34 & 15.5 \\
Newspaper & 7 & 3.2 \\
Internet & 11 & 5.0 \\
Teacher & 40 & 18.2 \\
Parents & 4 & 1.8 \\
Total & 186 & 84.5 \\
Missing System & 34 & 15.5 \\
\hline
\end{tabular}




\begin{tabular}{|l|c|c|}
\hline Types of Emergency Contraception which you know \\
\hline I-Pill & 141 & 64.0 \\
Econ & 45 & 20.5 \\
Don't Know & 34 & 15.5 \\
\hline Are Emergency Contraception used within 72 hours of sexual intercourse? \\
\hline Yes & 187 & 85.0 \\
No & 33 & 15.0 \\
\hline Are Emergency Contraception used to prevent unwanted pregnancy? & 93.2 \\
\hline Yes & 205 & 6.8 \\
No & 15 & 52.7 \\
\hline Emergency Contraception is not used when pregnancy is suspected & 116 \\
\hline Yes & 104 & 47.3 \\
No & 220 & 100 \\
\hline
\end{tabular}

Table-2 shows that majority $186(84.5 \%)$ respondents have heard of emergency contraception while $(24.5 \%)$ of the respondents first heard of emergency contraception from their friends and $40(18.2 \%)$ heard from their teacher. Most of the respondents141 (64\%) know the name of I-pill and 45 (20.5\%) were Econ. Majority 205 (93.2\%) of the respondents said that emergency contraception is used to prevent unwanted pregnancy and $187(85.0 \%)$ of them opined that emergency contraception is used within 72 hours of unsafe sexual intercourse. More than half $116(52.7 \%)$ of them said that emergency contraception is not used when pregnancy is suspected while less than half 104 (47.3\%) are against that.

Table -3 Respondents Perception towards Emergency Contraception $(\mathrm{n}=220)$

\begin{tabular}{|l|c|c|}
\hline Variables & Frequency & Percentage \\
\hline I can use Emergency Contraception if I Needed & 153 & 69.5 \\
\hline Agree & 23 & 10.5 \\
Disagree & 44 & 20.0 \\
Undecided & & \\
\hline Emergency Contraception is not effective & 90 & 40.9 \\
\hline Agree &
\end{tabular}




\begin{tabular}{|c|c|c|}
\hline Disagree & 89 & 40.5 \\
\hline Undecided & 41 & 18.6 \\
\hline \multicolumn{3}{|c|}{ Emergency Contraception is taken only by girls having many sexual partners } \\
\hline Agree & 106 & 48.2 \\
\hline Disagree & 67 & 30.5 \\
\hline Undecided & 47 & 21.4 \\
\hline \multicolumn{3}{|c|}{ Emergency Contraception should be used by married couple only } \\
\hline Agree & 69 & 31.4 \\
\hline Disagree & 121 & 55.0 \\
\hline Undecided & 30 & 13.6 \\
\hline \multicolumn{3}{|c|}{ It is a sin to use Emergency Contraception } \\
\hline Agree & 46 & 20.9 \\
\hline Disagree & 139 & 63.2 \\
\hline Undecided & 35 & 15.9 \\
\hline \multicolumn{3}{|c|}{ Emergency Contraception will help to reduce abortion and its resultant effect } \\
\hline Agree & 192 & 87.3 \\
\hline Disagree & 12 & 5.5 \\
\hline Undecided & 16 & 7.3 \\
\hline Total & 220 & 100 \\
\hline
\end{tabular}

Table 3 shows that the majority of $153(69.5 \%)$ of the respondents agreed that they can use emergency contraception if needed. About half 106 (48.2\%) of the respondents agreed to the opinion that emergency contraception is taken only by girls having many sexual partners. 90 (40.9\%) of the respondents stated that emergency contraception is effective and around the same proportion of the respondents $89(40.5 \%)$ are said not effective. More than half 121 (55.0\%) of the respondents affirmed that emergency contraception should not be used by the married couple only and $139(63.2 \%)$ said it is not a sin to use emergency contraception. Majority 192 (87.3\%) of the respondents agreed that emergency contraception will help to reduce abortion and its resultant effects. 
Table-4 Socio-demographic characteristics and their association with information on Emergency Contraception $(\mathrm{n}=220)$

\begin{tabular}{|c|c|c|c|c|}
\hline \multirow[t]{2}{*}{ Variables } & \multicolumn{2}{|c|}{ Information about Emergency Contraceptive } & \multirow{2}{*}{$\begin{array}{l}\text { Chi-Square } \\
\text { Value }\end{array}$} & \multirow[t]{2}{*}{ P-Value } \\
\hline & Heard about EC & Not Heard EC & & \\
\hline \multicolumn{5}{|l|}{ Age Group } \\
\hline Age $14-15$ & $3(1.61)$ & $2(5.88)$ & \multirow{3}{*}{2.972} & \multirow{3}{*}{0.116} \\
\hline Age 16-17 & $89(47.85)$ & $18(52.94)$ & & \\
\hline Age 18-19 & $94(50.54)$ & $14(41.18)$ & & \\
\hline \multicolumn{5}{|c|}{ Educational Status } \\
\hline Grade Eleven & $89(47.85)$ & $18(52.94)$ & & \\
\hline Grade Twelve & $97(52.15)$ & $16(47.06)$ & 0.298 & -0.37 \\
\hline \multicolumn{5}{|l|}{ Religion } \\
\hline Hindu & $139(74.72)$ & $30(88.24)$ & \multirow{4}{*}{3.102} & \multirow{4}{*}{0.119} \\
\hline Buddhist & $27(14.57)$ & $2(5.88)$ & & \\
\hline Christian & $13(6.98)$ & $1(2.94)$ & & \\
\hline Kirat & $7(3.73)$ & $1(2.94)$ & & \\
\hline \multicolumn{5}{|c|}{ Caste/Ethnicity } \\
\hline Chhetri & $65(34.95)$ & $13(38.23)$ & \multirow{10}{*}{5.861} & \multirow{10}{*}{0.163} \\
\hline Brahmin & $34(18.28)$ & $7(20.58)$ & & \\
\hline Newar & $15(8.06)$ & $4(11.77)$ & & \\
\hline Tamang & $26(13.98)$ & $1(2.94)$ & & \\
\hline Gurung & $5(2.69)$ & $1(2.94)$ & & \\
\hline Rai/Limbu & $14(7.53)$ & $3(8.83)$ & & \\
\hline Magar & $9(4.83$ & $3(8.83)$ & & \\
\hline Sherpa & $4(2.15)$ & 0 & & \\
\hline Dalit & $11(5.92)$ & $1(2.94)$ & & \\
\hline Tharu & $3(1.62)$ & $1(2.94)$ & & \\
\hline Total & 186 & 34 & & \\
\hline
\end{tabular}


Table 4 shows a clear association between information on emergency contraception and other socio-demographical variables such as the age of the students, level of education, the religion of students, and the caste/ethnicity of students. The Pvalue calculated between the age of respondents and information of emergency contraception was found to be 0.116 which not significant to establish the association between these two variables. The P-Value calculated between education level and information of emergency contraception was -0.37 which was significant to establish the association between these two variables. There is an association between age and information on emergency contraception. The respondents' age $18-19$ were $(50.54 \%)$ heard of emergency contraception than age 16-17 were $(47.85 \%)$ heard. Education is also playing a vital role in information about emergency contraception. More than half percentage of female adolescent students from grade twelve $(52.15 \%)$ heard about emergency contraception compared to those who were from grade eleven $(47.85 \%)$.

\section{Discussion}

This study investigated female adolescent information and perception of emergency contraception. The findings of this study indicate that information on emergency contraception were relatively high but had found negative perception regarding emergency contraception among the female adolescent students of secondary school. A similar study conducted among college students in Kathmandu district reported (68\%) participants were heard about emergency contraception (Adhikari, 2009) and other studies done in Nigeria 75\% (Somnath, 2001), Addis Ababa 43\% (Wegene \& Fikre, 2007), Jima 41.9\% (Nasir, 2010) but in this study results were $(84.5 \%$ ) higher than that study and lower than health science and medical students of Arba Minch University which has 95.9\% (Fekadu, 2017). A large number of adolescents' girls heard about emergency contraception from their friends $(24.5 \%)$ and few had heard it from parents $(1.8 \%)$. These findings suggest that peer education approaches might be helpful for information regarding emergency contraception among adolescents' girl. The result showed that the majority $(49.1 \%)$ of the respondents were within the age group range 18-19 years. Concerning the religion of the adolescents' girl student majority $(76.8 \%)$ was Hindu only $(6.4 \%)$ was Christian. Contrary findings were found in the study, the majority of adolescents' girl's students were Christian (64\%) religion which was done in Trinidad (Parey et al., 2010). The level of 
Information regarding emergency contraception was not statistically significant with a range of age $(\mathrm{P}=0.116)$ neither religion $(\mathrm{P}=0.119)$ nor caste/ethnicity $(\mathrm{P}=0.163)$ but the level of information regarding emergency contraception was significant with the level of education $(\mathrm{P}=-0.37)$. This means education providing more information towards female adolescent students. The majority $(69.5 \%)$ of the female adolescent students had a positive perception towards emergency contraception as they would use it if they required. A majority (87.3\%) of the respondents agreed that emergency contraception will help to reduce abortion and its resultant effects.

\section{Conclusion}

It can be concluded from this study that information about emergency contraception was high while perception towards emergency contraception was comparatively negative. Health education intervention to information and for positive perception towards emergency contraception is important to female adolescent students of secondary school. Formal and informal sexual and reproductive health education classes are necessary for the school including emergency contraception. This would be helpful to reduce misconceptions about emergency contraception among female adolescent students of secondary school. To change the perception towardsemergency contraception and further increase the level of information and usage collaborated health education and media workers are highly recommended.

\section{References}

Abraha, D. Welu, G. Berwo, M. et al. (2019). Knowledge and utilization of emergency contraceptive and its associated factors among women seeking induced abortion in public hospitals Eastern Tigray, Ethiopia, 2017: A cross-sectional study. BioMed Research International (3), 1-7.

Adhikari, R. (2009). Factors affecting awareness of emergency contraception among college students in Kathmandu, Nepal. BMC Women's Health, 9:27.

Centre for Research on Environment, Health and Population Activities, (2004). Public Opinion Poll on Abortion Law and Service. Kathmandu, Nepal.

CREHPA, (2006). Unsafe Abortion: Nepal Country Profile Government of Nepal. Kathmandu. 
Dessie, A. (2009). Assessment of factors associated with awareness, attitude and utilization of emergency contraceptive among female Debremrkose College students.

Elizabeth, G. \& James, T. (2012). Emergency contraceptive a lastchance to prevent unintended pregnancy, 1-28, Princeton University.

Family Health Division, (2005). A country Profile: Adolescent Health and Development in Nepal. Status, Issues, Programme and Challenges. Kathmandu, Nepal.

Family Health Division, (2000). National adolescent health and development strategy. Kathmandu, Government of Nepal.

Fekadu, Y. (2017). Knowledge attitude andutilization of emergency contraception among health sciences and medical students of Arba Minch University, 2015.J. Women's Health Care 6, 383.

Khatiwada et al., (2013).Sexual and Reproductive Health of Adolescents and Youth in Nepal: Trends and Determinants. Nepal Demographic and Health Survey. Kongnyuy et al., (2007). A survey of knowledge, attitudes and practice of emergency contraception among university students in Cameroon. Emerg Med. 7,7.

Ministry of Health and Population, (2011). New ERA, ICF International Inc. Nepal Demographic and Health Survey. Ministry of Health and Population.

Nasir, T. (2010).KAP on emergency contraceptive in Jimma University.Ethiopian J Health Science 20, 2.

Pathak, D. (2014). A Study on Knowledge, Attitude and Behavior on Emergency Contraception among Higher Secondary and Bachelor Level Youth Students of Lekhnath Municipality, Nepal. World Academy of Science, Engineering and Technology Medical and Health Sciences.

Parey et. al., (2010). Knowledge, Attitude and Practice of Emergency Contraceptive Pills among Tertiary Level Students in Trinidad: a cross-sectional survey. West Indian Med J. 59(6):650-5.

Somba et al., (2014). Sexual behavior, contraceptive knowledge and use among female undergraduates' students of Muhimbili and Dares Salaam universities Tanzania: a Cross- section study. BMC Women's Health, 14:19.

Somnath, R. (2001). Emergency contraceptive in reproductive health care program introduction guideline. Health and population perspective 24, 109-136. 
Thapa, B. (2013). Knowledge and attitude regarding emergency contraception among nursing personnel. JCMC, 3(3) 46-50.

Thapa, S. Lopchan, M. and Mehta, R. (2015). Knowledge and attitude regarding emergencycontraception among higher secondary students. JNHS.4(3): 46-49.

United Nation, (2011).World Population Prospects: The 2010 Revision, CD-ROM edition. New York: United Nation; Department of Economic and Social Affairs, Population Division.

Wegene, T. and Fikre, E. (2007). Knowledge, attitude and practice on emergency contraceptive among female university students in Addis Ababa. Ethiopian J Health Development 21, 2.

WHO, (2001).The second decade: Improving adolescent health and development. Geneva, WHO. 